\title{
ROLE OF PRE-OPERATIVE UPPER GASTRO-INTESTINAL ENDOSCOPY IN SYMPTOMATIC PATIENTS UNDERGOING ELECTIVE LAPAROSCOPIC CHOLECYSTECTOMY FOR GALL BLADDER STONE DISEASE
}

\author{
Anil Kumar Parappa Bellad1, Manish Chandrashekar Asha² \\ ${ }_{1}^{1}$ Associate Professor, Department of General Surgery, KLE's Dr. Prabhakar Kore Hospital and Medical Research Center, Belgaum, \\ Karnataka, India. \\ 2Postgraduate Student, Department of General Surgery, KLE's Dr. Prabhakar Kore Hospital and Medical Research Center, Belgaum, \\ Karnataka, India.
}

ABSTRACT
BACKGROUND
Gallbladder stone disease is one of the most common problems encountered in surgical practice. The diagnosis of gallbladder stone
disease has increased over the last decade because of the ease of access to sonography. A percentage of patients do not get relief
after surgery for gallstone disease. The sonographic finding of gallbladder calculi may be incidental and acid peptic disease of the
stomach or the duodenum, reflux disease or hiatus hernia may be the true cause of pain. Upper abdominal pain may be secondary
to either cholelithiasis or gastro duodenal diseases. Differentiating between these two is important, because the prevalence of
these conditions is common in the general population. Thus, this study aims to determine the importance of upper gastro intestinal
endoscopy to reveal the association between dyspeptic symptoms and diseases with gallbladder calculi.

\section{METHODS}

This is a prospective study conducted on 66 cases of ultrasound proven gallstone disease, at the department of general surgery, Dr. Prabhakar Kore Hospital and Medical Research Center irrespective of age and sex. After examination, all patients were subjected to Upper GI endoscopy. The statistical analysis was conducted using SPSS version 22.

\section{RESULTS}

Out of 66 study samples, symptomatology has shown atypical biliary colic accounting for $54.5 \%$ in comparison to typical biliary colic of $45.5 \%$. All subjects were subjected to upper GI endoscopy which detected a total number of 24 samples having positive upper GI lesions accounting for $36.4 \%$, which is statistically significant $(\mathrm{p}=0.045)$ and $63.6 \%$ being normal on endoscopy.

\section{CONCLUSIONS}

We recommend an UGI-Scopy pre-operatively for patients undergoing elective laparoscopic cholecystectomy for gallbladder stone disease for adequate diagnosis and treatment of the co-existing UGI lesions if present and reduce the incidence of post-operative persistence of symptoms.

HOW TO CITE THIS ARTICLE: Bellad AKP, Asha MC. Role of pre-operative upper gastro-intestinal endoscopy in symptomatic patients undergoing elective laparoscopic cholecystectomy for gall bladder stone disease. J. Evolution Med. Dent. Sci. 2019;8(20): 1598-1601, DOI: $10.14260 / \mathrm{jemds} / 2019 / 354$

\section{BACKGROUND}

Gallbladder stone disease is one of the most common problems encountered in surgical practice. Gallbladder calculi constitute a significant health problem in developed countries, affecting $10 \%$ to $15 \%$ of the adult population ${ }^{1}$. In Asia, the prevalence of gallstone disease is $5-10 \%$ of population especially among older individuals and females. The number of surgeries for Gallbladder stone disease has risen markedly in developed countries since 1950. The introduction of laparoscopic cholecystectomy in 1989 further increased the cholecystectomy rate. ${ }^{1}$

The diagnosis of gallbladder stone disease has steadily increased because of the common access to sonography. The vast majority of cholecystectomies are performed for gallbladder calculi with cholesterol stones accounting for nearly $75 \%$ of all gallstones. ${ }^{2}$

'Financial or Other Competing Interest': None.

Submission 01-04-2019, Peer Review 03-05-2019,

Acceptance 09-05-2019, Published 20-05-2019.

Corresponding Author:

Dr. Manish Chandrashekar Asha,

\#135, $1^{\text {st }}$ Main $2^{\text {nd }}$ A Cross,

Sadashivanagar, Belgaum-590010,

Karnataka, India.

E-mail: manishrules001@gmail.com

DOI: $10.14260 /$ jemds $/ 2019 / 354$

\section{(c) (i) $\$$}

Gallstones are common the majority will be asymptomatic: up to $80 \%$ will never experience biliary colic or complications such as acute cholecystitis, cholangitis, or pancreatitis. ${ }^{3}$ Hence, most gallbladder calculi are clinically "silent" an incidental finding often uncovered during abdominal sonography being performed for another reason. Since most gallbladder calculi are asymptomatic, it is essential to define exactly which symptoms are caused by gallbladder calculi: true biliary colic and/or complications, versus vague abdominal complaints including dyspeptic symptoms. The importance for clarifying what constitutes true biliary colic is to better predict relief following surgery.

Cholecystectomy proved successful in treating the patients of biliary colic and cholecystitis in $80-95 \%$ of patients with calculi. When calculi were not present, the presence of symptoms was as high as $40 \%{ }^{4}$ The persistence of abdominal symptoms even after cholecystectomy is highly discouraging for surgeons. Coexistence of concurrent upper gastrointestinal problems in gallbladder calculi patients may have attributed to the post cholecystectomy syndrome. 5

Post-cholecystectomy syndrome (PCS) consists of a group of upper gastro-intestinal symptoms that recur and/or persist. After cholecystectomy. It is defined. as early if occurring in the post-operative period and late if it manifests after months or years. Although this term. Is used widely, it is not completely accurate as it includes a large number of 
disorders, both biliary and extra-biliary in origin, that may be unrelated to surgery for cholelithiasis. ${ }^{6}$

To identify the cause of right upper abdominal pain, oesophagogastroduodenoscopy (Upper GI endoscopy) is important to identify the diseases of upper gastrointestinal tract. As it evaluates the mucosa for signs of disease from the esophagus through the duodenum \& allows direct visualization of the ampulla Of Vater.7

These upper gastrointestinal symptoms have been. related to gallbladder calculi but causal relationship has not been established yet. Evaluation of gall stone disease is an immense challenge as to ascertain whether gallstones are responsible for symptoms or just an incidental finding and acid peptic disease of the stomach or the duodenum, reflux disease or hiatus hernia may be the true cause of pain.

Thus, this study tries to seek the importance of upper gastro intestinal endoscopy to reveal the association between gastrointestinal symptoms and diseases with gallbladder calculi to establish a plan of treatment which is one of the most common problems faced by the current surgeon, for the complete cure of all patients.

\section{METHODS}

This is a hospital based one year, observational, crosssectional, hospital based, study conducted in KLES Dr. Prabhakar Kore Hospital. The study was conducted between January 2017 to December 2017.

\section{Source of Data}

All symptomatic patients getting admitted to the surgery wards, in KLES Dr. Prabhakar Kore Hospital with ultrasonographically proven Gall Bladder Stone Disease, who merit surgery.

\section{Inclusion Criteria}

All symptomatic patients having GB stone disease proven by ultrasonography who merit surgery.

\section{Exclusion Criteria}

- Acute abdomen.

- $\quad$ CBD stones.

- $\quad$ Obstructive jaundice.

- Cholangitis.

- GB stone pancreatitis.

- GB neoplasm.

- Previous GB or pancreatic surgery.

\section{Rationale for Sample Size}

A study carried out by Mohamed Toum Musa M Ibrahim ${ }^{8}$ et al has observed that the pathological findings with upper GI endoscopy for all those diagnosed with Gall bladder stone disease was $60 \%$.

In our study expecting similar results with $95 \%$ confidence levels and $20 \%$ of relative precision in the result, the study requires a minimum of 66 subjects.

$\mathrm{n}=(\mathrm{Za})^{\wedge} 2[\mathrm{pXq}] / \mathrm{d}^{\wedge} 2$

$\mathrm{n}=2^{\wedge} 2[60 \mathrm{X} 40] / 12^{\wedge} 2$

$\mathrm{n}=9600 / 144$

$\mathrm{n}=66$.
This prospective study was conducted on the patients meeting the inclusion criteria, for patients attending the general surgery OPD at KLES Dr. Prabhakar Kore Hospital.

After clinical assessment, and ultrasonography, patients will be admitted and subjected to UGI scopy and a biopsy would be taken if necessary.

Institutional approval was taken for the study. Verbal and written informed consent were taken from each participant. The data collected from the patients includes personal information, presenting symptoms - typical (Biliary colic)/atypical (Vague upper abdominal symptoms), investigations including ultrasonography, Upper GI endoscopy findings biopsy reports if present.

UGE was performed in the endoscopy room 1-2. days prior to operation. The presence of ulcer and inflammation of gastric mucous membrane will be subjected to histopathological examination. The clinical symptoms will be categorized as typical or atypical based on the characters mentioned above. The endoscopic findings were divided as normal, inflammatory, erosions, ulcers and others including carcinomas. Similar categorizations were applied for histopathological findings as well.

\section{Statistical Analysis}

The statistical analysis will be performed using SPSS version 22. The findings of the study were cross tabulated using the SPSS 22 software and was analyzed using the Chi square test to obtain the $p$ value, and the association was considered significant if the p-value between the two variables was $<0.05$.

\section{RESULTS}

A total of 66 patients were included in the study from January 2017 to December 2017, their ages ranged from 16 to 81 years with a mean age of $45.8+/-16.5$. There was a total of 28 males and 38 females in the study.

The subject's symptomatology was divided into, Typical biliary colic, which is constant and increases in severity over the first half hour or so and typically lasts 1 to 5 hours. It is located in the epigastrium or right upper abdomen and frequently radiates to the right upper back or between the scapulae, and Atypical biliary symptoms, here the pain may be located primarily in the back or the left upper or lower right quadrant. Out of the 66 subjects 30 had typical symptoms and 36 had atypical symptoms.

\section{DISCUSSION}

Upper gastro intestinal endoscopy has been recommended pre operatively in patients undergoing elective laparoscopic cholecystectomy for gall bladder stone disease by Thybusch et al., ${ }^{9}$ Sosada et al.10 and many others to diagnose the coexistent UGI lesions in these patients, which otherwise went unnoticed and led to persistence of the patient's symptoms post-surgery.

A total of 66 patients were included in the study, the age of the patients ranged from 16-81 years, and most of the patients belonged to the 46-60 age group, the mean age of the patients was 45.8 years, which is comparable to other studies $(40.6) \cdot{ }^{11}$ 


\begin{tabular}{|c|c|c|c|c|}
\hline Sex & $\begin{array}{c}\text { Typical Biliary } \\
\text { Symptoms }\end{array}$ & $\begin{array}{c}\text { Atypical Biliary } \\
\text { Symptoms }\end{array}$ & Total & $\begin{array}{c}\text { p- } \\
\text { Value }\end{array}$ \\
\hline Male & $15(53.5 \%)$ & $13(46.5 \%)$ & $\begin{array}{c}28 \\
(100 \%)\end{array}$ & 0.256 \\
\hline Female & $15(39.5 \%)$ & $23(60.5 \%)$ & $\begin{array}{c}38 \\
(100 \%)\end{array}$ & \\
\hline Total & $\mathbf{3 0}(45.5 \%)$ & $\mathbf{3 6}(54.5 \%)$ & $\begin{array}{c}\mathbf{6 6} \\
(\mathbf{1 0 0} \%)\end{array}$ & \\
\hline \multicolumn{6}{|c|}{ Table 1. Sex Wise Distribution of Biliary Symptoms } \\
\hline
\end{tabular}

\begin{tabular}{|c|c|c|}
\hline UGI Scopy Findings & FrequencyPercent \\
\hline Lax Cardia, Fundal Gastritis & & \\
Chronic Diffuse Erosive Gastritis & & \\
Lax Cardia, Grade B Esophagitis & 7 & $10.6 \%$ \\
Scattered Gastric Erosions in Fundus and & 1 & $1.5 \%$ \\
antrum & 5 & $7.8 \%$ \\
Periampullary Diverticulum in Second & 2 & $3.0 \%$ \\
part of Duodenum & 1 & $1.5 \%$ \\
Lax Cardia, Fundal Gastritis, Grade A & 3 & $4.5 \%$ \\
Esophagitis & 2 & $3.0 \%$ \\
Diffuse Chronic Gastritis & 1 & $1.5 \%$ \\
Lax Cardia, Bile Reflux Esophagitis, & 1 & $1.5 \%$ \\
Duodenitis. & 1 & $1.5 \%$ \\
Lax Cardia, Hiatus Hernia & 42 & $63.6 \%$ \\
Bile Reflux Gastritis & & \\
Normal & & \\
Total & $\mathbf{6 6}$ & $\mathbf{1 0 0 \%}$ \\
\hline
\end{tabular}

Table 2. Relationship between Biliary Symptoms and UGIScopy Findings
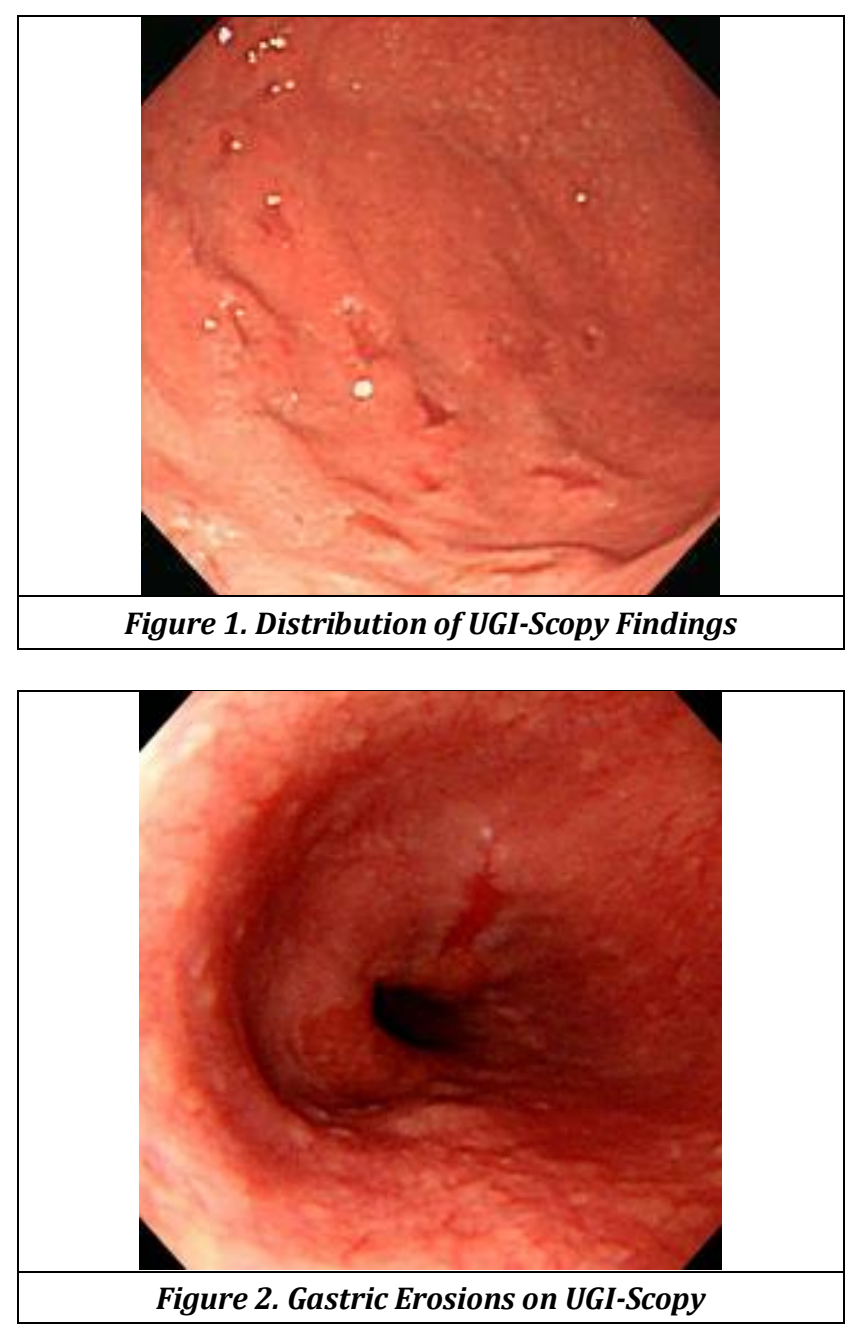

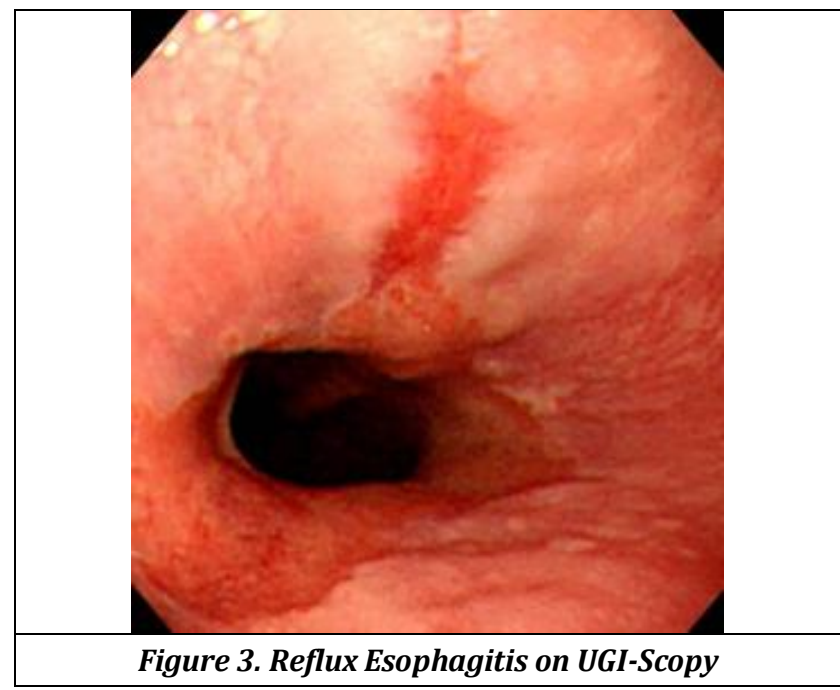

Among the 66 study subjects $36.4 \%(n=24)$, were found to have positive UGI scopy findings, out of which $29.2 \%(n=7)$ had typical biliary colic and $70.8 \%(n=17)$ had atypical biliary symptoms.

In comparison with this $63.6 \%(n=42)$ of the study subjects had normal UGI scopy findings, out of which $54.8 \%$ $(n=23)$ had typical biliary colic and 45.2\% ( $n=19)$ had atypical biliary colic.

Inferring that the chances of yielding a positive UGI scopy is higher in patients with atypical biliary symptoms.

Female preponderance was noted in the study with $57.6 \%(n=38)$ females and $42.4 \%(n=28)$ males, with a male to female ratio of $1: 1.3$, which is strongly supported by many studies. Rashid et al.12 also published similar results with male to female ratio 1:4.

This study has shown that majority of the patients $54.5 \%$ $(\mathrm{n}=36)$ presented with atypical biliary symptoms, as compared to patients who presented with typical biliary colic, $(45.5 \%, \mathrm{n}=30)$.

This study found that $36.4 \%(n=24)$ of the study subjects had positive UGI-scopy findings, which is statistically significant with a $\mathrm{p}$ value of 0.045 .

This result is supported by-

- Study performed by Diettrich et al.13 also suggested $31 / 100$ patients had abnormalities on UGI-SCOPY.

- $\quad$ Schwenk et al. ${ }^{14}$ suggested that $30.2 \%$ (345 patients) had pathological findings.

- Rassek et al.15 recommends that investigation of the upper gastrointestinal tract must precede an elective cholecystectomy, as his study showed that $44 \%$ of patients had positive UGI-SCOPY findings.

It has been observed from this study that the prevalence of typical biliary colic is higher among the young (16-30 years) as compared to atypical symptoms i.e., $73.3 \%$ and $26.7 \%$ respectively, while on the other hand atypical biliary symptoms is more common in the older age group (61-75 years) than typical biliary colic i.e. $69.2 \%$ and $30.8 \%$ respectively.

Among the 66 study subjects, $39.5 \%$ and $60.5 \%$ of the females had typical and atypical biliary symptoms respectively, whereas $53.5 \%$ and $46.5 \%$ of males had typical and atypical symptoms respectively. But the sex wise 
distribution of symptoms was almost equal and not statistically significant with a p value of 0.256 .

Among the 66 study subjects $36.4 \%(n=24)$, were found to have positive UGI scopy findings, out of which $29.2 \%(n=7)$ had typical biliary colic and $70.8 \%(n=17)$ had atypical biliary symptoms. In comparison with this $63.6 \%(n=42)$ of the study subjects had normal UGI scopy findings, out of which $54.8 \%(n=23)$ had typical biliary colic and $45.2 \%(n=19)$ had atypical biliary colic. Inferring that the chances of yielding a positive UGI scopy is higher in patients with atypical biliary symptoms. In a similar study by Mohamad Mozafar and his colleague's et al. ${ }^{16}$ they found that, among the 178 patients with atypical pain, 148 (83\%) had abnormal findings in UGIScopy.

In another study Faisal et.al. 17 concluded that $77.2 \%$ of their patients with typical symptoms had positive UGI-Scopy findings.

Karmacharya A et al ${ }^{18}$ have observed that normal UGI findings are seen in patients with typical pain reinforcing the fact that patients with typical abdominal pain has less likelihood of presenting with coexisting upper gastrointestinal lesion as evidenced in other studies.

Sosada et al. ${ }^{10}$ observed in his study gastric ulcer in 179 (6.4\%), duodenal ulcer in 127 (4.5\%), gastritis in 375 (26.3\%), polyps in $143(5.1 \%)$ and cancer in $3(.1 \%)$ patients. Similarly in this study UGI-scopy showed lax cardia and fundal gastritis in 7 (10.6\%), chronic diffuse erosive gastritis in $1(1.5 \%)$, lax cardia and grade b esophagitis in $5(7.8 \%)$, scattered gastric erosions in fundus and antrum in $2(3.0 \%)$, periampullary diverticulum in second part of duodenum in 1 (1.5\%), lax cardia with fundal gastritis and grade a esophagitis in $3(4.5 \%)$, diffuse chronic gastritis in $2(3.0 \%)$, lax cardia with bile reflux esophagitis and duodenitis in 1 $(1.5 \%)$, lax cardia and hiatus hernia in $1(1.5 \%)$, bile reflux gastritis in $1(1.5 \%)$.

\section{CONCLUSIONS}

Increased access to ultrasound for patients presenting with pain abdomen, has led to an increase in the diagnosis of cholelithiasis, as its symptomatology overlaps many upper GI lesions, the incidental finding of gall stones on ultrasound may mask the co-existing UGI lesions.

In this study, UGI lesions were found in $36.4 \%$ of the patients. Hence treating either one of them will lead to persistence of symptoms post treatment.

Thus, we recommend an UGI-Scopy pre-operatively for patients undergoing elective laparoscopic cholecystectomy for gallbladder stone disease for adequate diagnosis and treatment of the co-existing UGI lesions if present and reduce the incidence of post-operative persistence of symptoms.

\section{REFERENCES}

[1] Stinton LM, Shaffer EA. Epidemiology of gallbladder disease: cholelithiasis and cancer. Gut Liver 2012;6(2):172-87.

[2] Glambek I, Arnesjo B, Soreide O. Correlation between gallstones and abdominal symptoms in a random population. Results from a screaning study. Scand J Gasrtoentrol 1989;24(3):277-81.
[3] Gibney EJ. Asymptomatic gallstones. $\mathrm{Br}$ J Surg 1990;77(4):368-72.

[4] Janowitz P, Kratzer W, Zemmler T, et al. Gallbladder sludge: spontaneous course and incidence of complications in without stones. Hepatology 1994;20(2):291-4.

[5] Kraag N, Thijs C, Knipschild P. Dyspepsia - how noisy are gallstones? A meta-analysis of epidemiologic studies of biliary pain, dyspeptic symptoms, and food intolerance. Scand J Gastroenterol 1995;30(5):411-21.

[6] Murshid KR. The post cholecystectomy syndrome: a review. Saudi J Gastroenterol 1996;2(3):124-37.

[7] Talley NJ. Gallstones and upper abdominal discomfort, Innocent bystander or a cause of dyspepsia? J Clin Gastroenterol 1995;20(3):182-3.

[8] Ibrahim MTM, Khair RZAM, El-Hadi YM, et al. Upper gastrointestinal endoscopic findings in patients with gallstone disease. Khartoum Medical Journal 2012;5(2):749-52.

[9] Thybusch A, Schaube H, Schweizer E, et al. Significant value and therapeutic implications of routine gastroscopy before cholecystectomy. J Chir (Paris) 1996;133(4):171-4.

[10] Sosada K, Zurawinski W, Piecuch J, et al Gastroduodenoscopy: a routine examination of 2, 800 patients before laparoscopic cholecystectomy. Surg Endosc 2005;19(8):1103-8.

[11] GREPCO. The epidemiology of gallstone disease in Rome, Italy. Part I. Prevalence data in men. Hepatology 1988;8(4):904-6.

[12] Rashid F, Rashid N, Waraich N, et al. Role of routine oesophagogastroduodenoscopy before cholecystectomy. Int J Surg 2010;8(3):236-8.

[13] Diettrich H, Wundrich B, Kobe E, et al. Gastroscopy before cholecystectomy. Gastroenterol J 1990;50(4):173-4.

[14] Schwenk W, Bohm B, Badke A, et al. Preoperative esophagogastroduodenoscopy before elective surgical therapy of symptomatic cholelithiasis. Leber Magen Darm 1992;22(6):225-9.

[15] Rassek D, Osswald J, Stock W. Routine gastroscopy before cholecystectomy. Chirurg 1988;59(5):335-7.

[16] Mozafar M, Sobhiyeh M, Heibatollahi M. Is esophagogastroduodenoscopy essential prior to the elective surgical therapy of symptomatic cholelithaisis? Gastroenterology and Hepatology From Bed to Bench 2010;3(2):77-82.

[17] Faisal A, Gadallah AN, Omar SA, et al. The role of upper gastrointestinal endoscopy in prevention of postcholecystectomy pain prior the elective surgical therapy of chronic cholecystitis. Med J Cairo Univ 2013;81(1):289-93.

[18] Karmacharya A, Malla BR, Joshi HN, et al. The predictive value of pre-operative symptoms including upper gastrointestinal endoscopy before laparoscopic cholecystectomy for elective symptomatic cholecystolithiasis. Kathmandu Univ Med J 2013;11(4):300-4. 